\title{
Ototoxicity of acetic acid on the guinea pig cochlea
}

Takafumi Yamano ${ }^{1,2^{*}}$, Hitomi Higuchi ${ }^{2}$, Takashi Nakagawa ${ }^{2}$ and Tetsuo Morizono ${ }^{3}$

\begin{abstract}
Background: To evaluate the ototoxicity of acetic acid solutions.

Methods: Compound action potentials (CAPs) of the eighth nerve were measured in guinea pigs before and after the application of acetic acid in the middle ear cavity. The $\mathrm{pH}$ values of the acetic acid solutions were $\mathrm{pH}$ 3.0, 4.0, and 5.0, and the application times were $30 \mathrm{~min}, 24 \mathrm{~h}$, and 1 week.

Results: Acetic acid solution ( $\mathrm{pH} 3.0, \mathrm{~N}=3$ ) for 30 min caused no significant elevation in CAP threshold at $4 \mathrm{kHz}$, but a significant elevation in the threshold was noted for $8 \mathrm{kHz}$ and clicks. Acetic acid solutions $(\mathrm{pH} 4.0 \mathrm{~N}=6,5.0$ $\mathrm{N}=5$ ) for 30 min caused no significant elevation in CAP. Acetic acid solution ( $\mathrm{pH} 4.0)$ for $24 \mathrm{~h}(\mathrm{~N}=5)$ caused significant elevations of the CAP threshold for $8 \mathrm{kHz}, 4 \mathrm{kHz}$, and for clicks. Acetic acid (pH 5.0) for $24 \mathrm{~h}(\mathrm{~N}=3)$ caused a significant elevation of the CAP threshold for $4 \mathrm{kHz}$, but not for $8 \mathrm{kHz}$ or clicks. Acetic acid (pH 5.0) for 1 week $(N=3)$ caused a small but significant elevation CAP the threshold for $8 \mathrm{kHz}$ and $4 \mathrm{kHz}$ tone bursts, but no significant change was noted for clicks.

Conclusions: We found a significant toxic effect of acetic acid in guinea pigs on eighth-nerve compound action potentials when the $\mathrm{pH}$ was 5.0 or lower. Clearly, the stronger the acidity, and longer the exposure time, the more the CAP threshold was elevated.
\end{abstract}

\section{Background}

The purpose of this study is to elucidate the effect of various acidity of acetic acid on the guinea pig cochlea. Ototoxicity of Burow's solution on the guinea pig cochlea was reported by us (1). Main ingredient of Burow's solution is $13 \%$ aluminum acetate. Original Burow's solution has a pH 3.5 which caused a significant reduction of compound action potential (CAP) when applied in the middle ear cavity for $30 \mathrm{~min}$, while a two fold diluted Burow's solution ( $\mathrm{pH}$ 4.4) caused no reduction in CAP threshold. No study has been performed to determine ototoxicity of acetic acid with various $\mathrm{pH}$.

\section{Methods}

This protocol was approved by Fukuoka University Animal Ethics Committee.

\footnotetext{
* Correspondence: yamano@college.fdcnet.ac.jp

${ }^{1}$ Section of Otorhinolaryngology, Department of Medicine, Fukuoka Dental

College, 2-15-1 Tamura,Sawara-ku, Fukuoka 814-0193, Japan

${ }^{2}$ Department of Otorhinolaryngology, Fukuoka University School of Medicine,

Jounan-ku Nanakuma 7-45-1, Fukuoka 814-0180, Japan

Full list of author information is available at the end of the article
}

\section{Animals}

To evaluate the ototoxicity of various acidity $(\mathrm{pH})$ of acetic acid, alubino Hartley guinea pigs of both genders (in total $N=30$ ) were used. Animals selected had an average body weight between 300 and $400 \mathrm{~g}$ and had a positive Prayer reflex.

\section{Acetic acid}

The test solution was freshly prepared by the Pharmacy Department of our University Hospital, and the $\mathrm{pH}$ was measured and adjusted to 3.0, 4.0, and 5.0, before each experiment. Osmotic pressure of acetic acid studied was $300 \mathrm{mOsm}$, the molecular weight was 60 .

\section{Surgical procedure}

The animals were anesthetized with sodium pentobarbital $(30 \mathrm{mg} / \mathrm{kg})$, and were secured in a custom-made head holder. Xylocaine (Astra Zeneca PLC, Osaka, Japan) $0.5 \%$ was infiltrated into the surgical area before making the skin incision for access to the middle ear cavity. The tympanic bulla was exposed using a retroauricular incision. A small hole, about $2 \mathrm{~mm}$ in diameter, 
was made using a dental drill, and the round window membrane was visualized with a $40 \times$ operating microscope.

\section{Sound system}

Asynchronous tone bursts of $4 \mathrm{kHz}, 8 \mathrm{kHz}(1-\mathrm{ms}$ rise and fall time, 10- ms plateau time), and click sounds were given as stimuli at a pulse rate of 20 per second, from $80 \mathrm{~dB}$ (re $20 \mu \mathrm{Pa})$ to thresholds with $10 \mathrm{~dB}$ decrements. The speaker used was a Telephonics TDH-39P, and the sound source was placed $10 \mathrm{~cm}$ away from the auricle. The free field sound pressure was monitored and calibrated with a Brüel \& Kjær half-inch condenser microphone.

\section{Recording system and CAP measurement}

An 0.08-mm-diameter Teflon-insulated silver wire with an exposed ball tip was carefully placed with a micromanipulator on the peripheral round window membrane. $\mathrm{An} \mathrm{Ag}-\mathrm{AgCl}$ reference electrode was placed in the neck muscles. The obtained CAP responses were averaged 200 times with a Traveler Express ER-22 (Biologic Systems Corp. USA.)

\section{Application of acetic acid}

After the initial CAP was measured, the middle ear cavity was filled with acetic acid of various acidity. The amount of fluid necessary to fill the middle ear cavity was about $0.2 \mathrm{mls}$. Prior to CAP measurement, middle ear cavity of each animal was thoroughly dried using a tissue paper wick. We evaluated the following: (1-3) the effect on the action potential threshold of acetic acid ( $\mathrm{pH} 3.0,4.0$, and 5.0) at $30 \mathrm{~min}$ after topical application, (4-5) the effect of $24 \mathrm{~h}$ application of acetic acid ( $\mathrm{pH} 4.0$, $5.0)$, (6) the effect of 1 week application of acetic acid (pH5.0).

\section{Analysis of the data}

A threshold response was defined as an N1-P1 signal with amplitude of $10 \mu \mathrm{V}$. The change in the sound pressure level in decibels before and after drug application was defined as a change in hearing. The threshold change before and after drug application was compared, and a paired $t$-test was used to define statistical significance.

\section{Bacteriology}

The bacteriostatic activity of acetic acid was studied using a disk diffusion assay. Bacteria obtained from patients of our clinic was two stocks of MRSA, which were diluted to $10^{6} \mathrm{FCU} / \mathrm{ml}$, and cultured on an agar plate for $24 \mathrm{~h}$. Acetic acid with $\mathrm{pH} 3.0,4.0,5.0$, either $50 \mu \mathrm{l}$ or $75 \mu \mathrm{l}$, was dropped on an $8 \mathrm{~mm}$ diameter disk, and placed on the agar plate. At another $24 \mathrm{~h}$, the diameter of zones of inhibition of bacterial growth on the agar plate was measured.

\section{Results}

Figure 1 shows changes in CAP threshold in decibel loss before and $30 \mathrm{~min}$ after saline control. No significant reduction in CAP was observed brfore and after saline application.

Figure 2 shows changes in CAP threshold in decibel loss from control at $30 \mathrm{~min}$. For $4 \mathrm{kHz}$, no significant elevation in CAP threshold was noted. For click stimulation and for $8 \mathrm{kHz}$, a significant elevation of the threshold was noted.

Figure 3 shows changes in CAP with acetic acid $\mathrm{pH} 4.0$ at $30 \mathrm{~min}$. No significant elevation in CAP threshold was noted at $30 \mathrm{~min}$. Significant difference exists between $\mathrm{pH} 3.0$ and $\mathrm{pH} 4.0$ solution at $30 \mathrm{~min}$. Figure 4 shows the results from acetic acid $\mathrm{pH} 5.0$ at 30 min. No change in CAP threshold was noted at $30 \mathrm{~min}$.

At $24 \mathrm{~h}$, acetic acid ( $\mathrm{pH} 4.0)$ caused significant elevation of CAP threshold for $8 \mathrm{kHz}, 4 \mathrm{kHz}$, and for click sounds (Fig. 5). Compared with the results at $30 \mathrm{~min}$, ototoxicity became evident at $24 \mathrm{~h}$.

At $24 \mathrm{~h}$, acetic acid ( $\mathrm{pH}$ 5.0) caused a significant elevation of CAP threshold with tone burst of $4 \mathrm{kHz}$, but no significant elevation for $8 \mathrm{kHz}$ or for click sounds (Fig. 6)

At 1 week, acetic acid ( $\mathrm{pH}$ 5.0) caused small but a significant elevation in CAP threshold for $8 \mathrm{kHz}$ and $4 \mathrm{kHz}$ tone burst. No significant change was noted for click sound (Fig. 7).

\section{Bacteriology}

The diameter of the zone of inhibition for two stocks of MRSA is shown in Table 1 . The zone of inhibition in $\mathrm{mm}$ is shown. The larger zones of inhibition indicate better antimicrobial effect. Either $50 \mu \mathrm{l}$ or $75 \mu \mathrm{l}$, was used. The diameter of the disk was $8 \mathrm{~mm}$. At $24 \mathrm{~h}$, Bacteriostatic activity was noted for $\mathrm{pH} 3.0,4.0$, and 5.0.

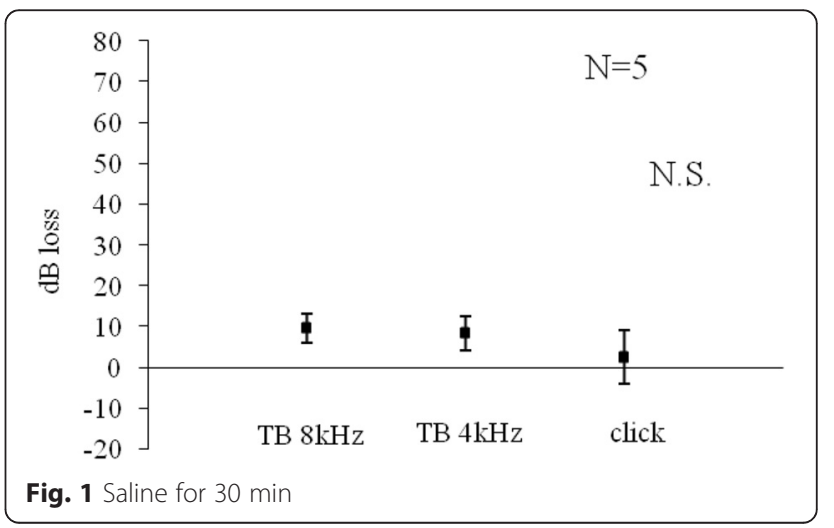




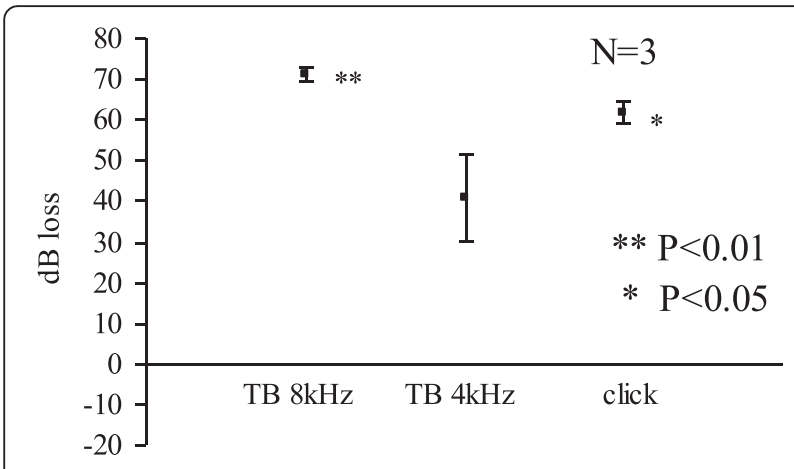

Fig. 2 Acetic acid (pH 3.0) $30 \mathrm{~min}$

The bacteriostatic activity was concentration dependent. A larger amount of acetic acid caused more bacteriostatic activity.

\section{Discussion}

The bactericidal effect of acetic acid has been well known empirically. Recently, Burrow's solution has gained popularity as effective solution in treating intractable ear discharge with fungi and with methicillin-resistant staphylococcus aureus (MRSA). The primary ingredient of this solution is acetic acid and $13 \%$ aluminum acetate. In our previous study [1], use of original Burrow's solution (pH3.5) for 30 min caused a significant elevation of CAP threshold, a two-fold diluted Burrow's solution ( $\mathrm{pH} 4.4)$ for 30 min caused no change in CAP threshold [1].

VoSol otic solution (ECR Pharmaceuticals Co. Inc) is a commonly available ear drops in the USA, which contains $2 \%$ acetic acid in a propylene glycol vehicle containing propylene glycol diacetate $(3 \%)$, benzentonoum chloride $(0.02 \%)$, and sodium acetate $(0.015 \%)$. This otic solution is buffered at $\mathrm{pH} 3.0$ for use in the external canal. Adverse effect of VoSol solution has been reported previously [2-4]. Application of $2 \%$ acetic acid or VoSol on the round window membrane caused a

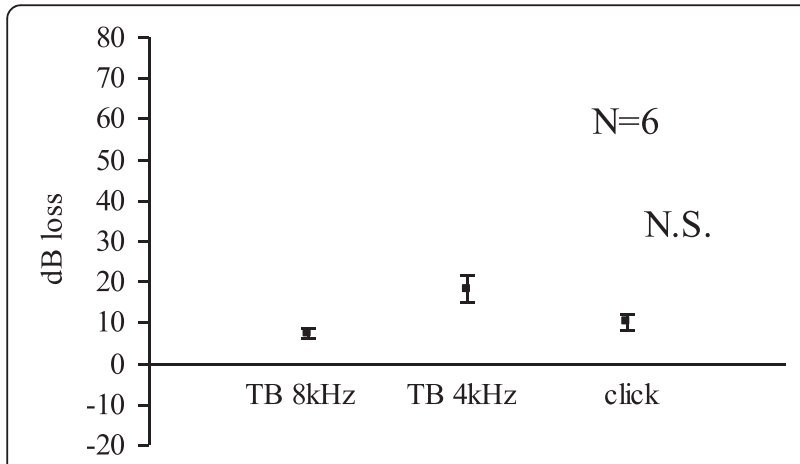

Fig. 3 Acetic acid (pH 4.0) $30 \mathrm{~min}$

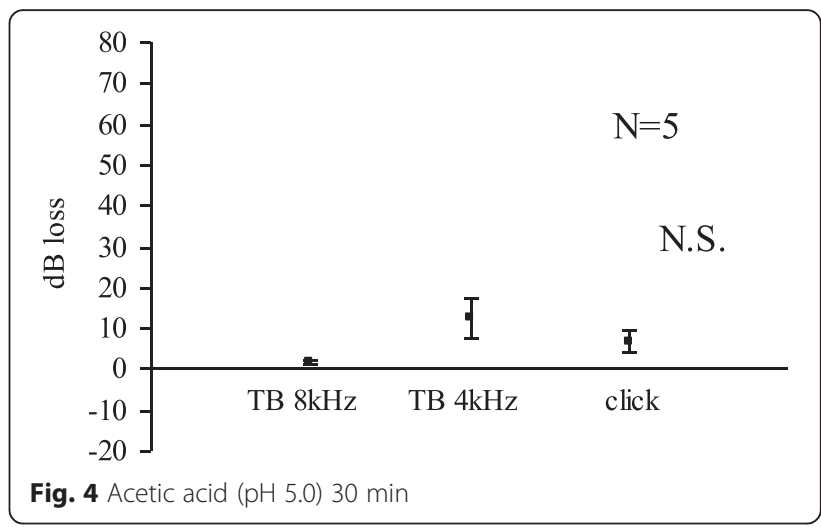

reduction of $\mathrm{pH}$ in the perilymph, in the endolymph, and a reduction of endocochlear DC potentials (EP). The reduction started only a few minutes after the application. They concluded that otic preparation containing acetic acid penetrates the round window membrane within a few minutes, and causes an inhibition of $\mathrm{Na}+$, K-ATPase activity of the stria vascularis. The effect was much stronger for the VoSol solution than for acetic acid, probably due to synergistic effects of acetic acid and propylene glycol. Propylene glycol causes damage of the round window membrane, thus the diffusion of acetic acid becomes greater.

Thorp et al [5-7] reported antibacterial activity of acetic acid and Burow's solution in vitro and also in vivo. However, otototoxic effect of this solution was not addressed. No systemic study has been performed to determine the ototoxicity of acetic acid alone.

We varied the $\mathrm{pH}$ of acetic acid to 3.0, 4.0, and 5.0. Also we varied the duration of acetic acid in the middle ear cavity for $30 \mathrm{~min}, 24 \mathrm{~h}$, and 1 week.

We found a significant toxic effect of acetic acid in guinea pigs on eighth nerve compound action potentials (CAP).

Clearly, stronger the acidity, more the elevation of CAP threshold, and longer the exposure time, more the elevation of CAP threshold.

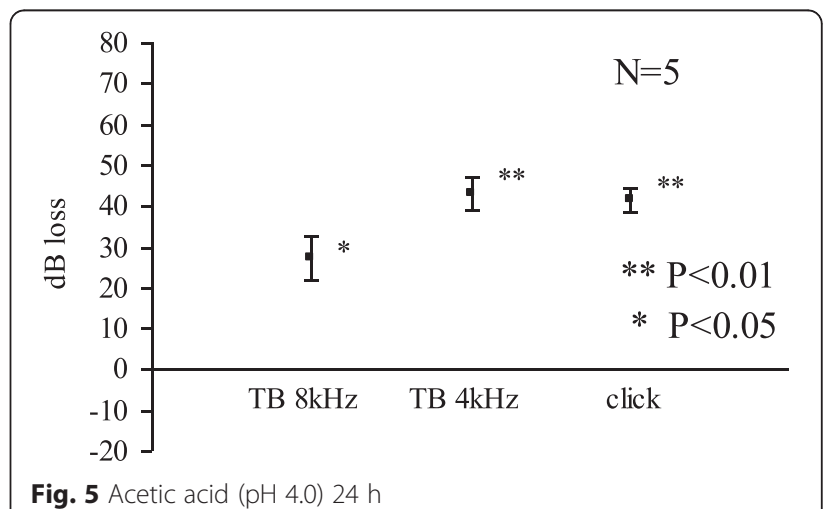




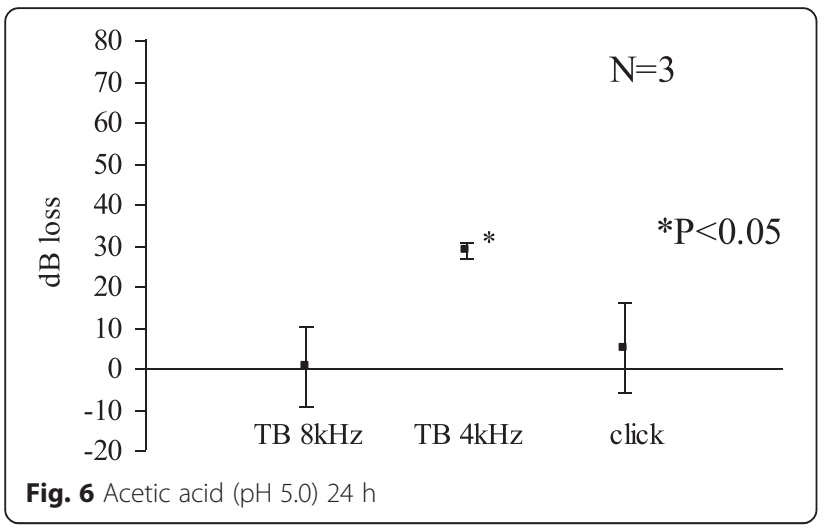

We limited the use of animals as small as possible yet to obtain significant results. In the Figs. 1, 2, 3 and 4, standard errors shown as a vertical line indicated that the variability of the change among animals in each groups is small.

In the group of Acetic acid (pH5.0) for 1 week, probably most of the acetic acid leaked out from Eustachian tube at the time we took the measurement. Also, tissue fluids from the middle ear mucosa would dilute the acetic acid. Comparison of the group of acetic acid (pH 5.0) for $30 \mathrm{~min}, 24 \mathrm{~h}$ and 1 week revealed that longer exposure time is more harmful to the cochlea, suggesting the toxic effect of the acetic acid is not reversible.

It is impossible to completely exclude the possibility of a conductive hearing loss caused by the fluid in the tympanic bulla. However, we believe conductive component of the hearing loss is minimum after drying the middle ear cavity with wicks of tissue paper.

Although acidic solutions have been used in the middle ear cavity as ear drops or irrigation, ototoxicity of the acidic solution has not been addressed adequately. Our previous study [1] showed Burrow's solution with $\mathrm{pH} 3.5$ for 30 min caused a significant reduction in CAP, yet a two-fold dilute Burrow's solution ( $\mathrm{pH}$ 4.4) for 30 min caused no reduction in CAP. Our current

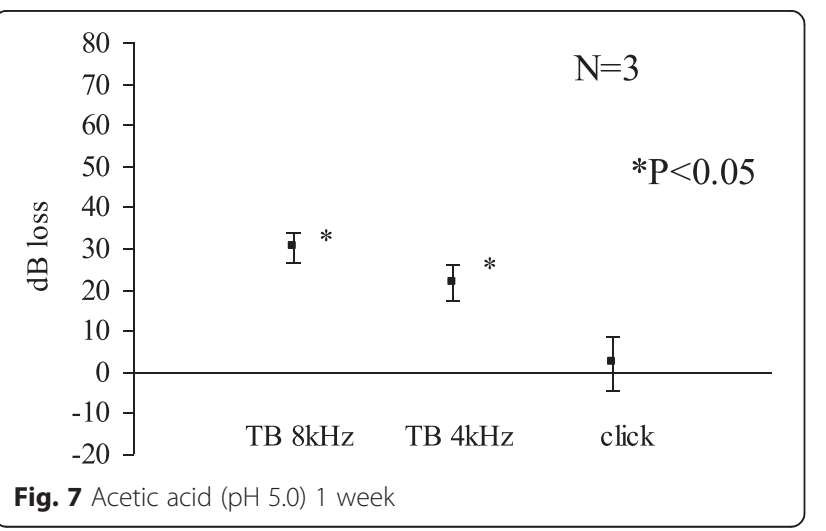

Table 1 Bacteriostatic activity for either 50 or $75 \mu$ of acetic acid

\begin{tabular}{lcccc}
\hline & & $\mathrm{pH} 3.0$ & $\mathrm{pH} 4.0$ & $\mathrm{pH} 5.0$ \\
\hline MRSA1 & $50 \mu \mathrm{L}$ & 35 & 32 & 21 \\
& $75 \mu \mathrm{L}$ & 39 & 33 & 26 \\
MRSA2 & $50 \mu \mathrm{L}$ & 37 & 30 & 23 \\
& $75 \mu \mathrm{L}$ & 40 & 35 & 26 \\
& & & & $(\mathrm{~mm})$ \\
\hline
\end{tabular}

experiment suggests ototoxicity becomes evident at $\mathrm{pH} 3.0$ at $30 \mathrm{~min}$, which is in good agreement with the previous study.

In the clinical settings, it is advisable to avoid allowing the solution to contact the round window membrane for extended times.

\section{Conclusions}

No systemic study has been performed to determine the ototoxicity of acetic acid alone. We varied the $\mathrm{pH}$ of acetic acid to 3.0, 4.0, and 5.0. Also we varied the duration of acetic acid in the middle ear cavity for $30 \mathrm{~min}$, $24 \mathrm{~h}$, and 1 week.

We found a significant toxic effect of acetic acid in guinea pigs on eighth nerve compound action potentials (CAP) when the $\mathrm{pH}$ is 5.0 or less. Clearly, stronger the acidity, more the elevation of CAP threshold, and longer the exposure time, more the elevation of CAP threshold.

\section{Competing interests}

The authors declare that they have no competing interests.

\section{Authors' contributions}

TY: data collection and review, conception of the study design, surgery and writing of the manuscript; $\mathrm{HH}$ : surgery and revision of the initial manuscript; $\mathrm{TN}$ : analysis and interpretation of data; TM: proposal of the study, surgery, and revision of the final manuscript. All authors read and approved the final manuscript.

\section{Author details}

${ }^{1}$ Section of Otorhinolaryngology, Department of Medicine, Fukuoka Dental College, 2-15-1 Tamura,Sawara-ku, Fukuoka 814-0193, Japan. ²Department of Otorhinolaryngology, Fukuoka University School of Medicine, Jounan-ku Nanakuma 7-45-1, Fukuoka 814-0180, Japan. ${ }^{3}$ Nishi Fukuoka Hospital, Nishi-ku Ikino-matsubara 3-18-8, Fukuoka 819-8555, Japan.

Received: 17 August 2015 Accepted: 10 December 2015

Published online: 14 December 2015

References

1. Sugamura M, Yamano $T$, Higuchi $H$, Takase $H$, Yoshimura $H$, Nakagawa $T$, et al. Ototoxicity of Burow solution on the guinea pig cochlea. Am J Otolaryngol. 2012;33:595-9.

2. Ikeda K, Morizono T. The preparation of acetic acid for use in otic drops and its effect on endocochlear potential and $\mathrm{pH}$ in inner ear fluid. Am J Otolaryngol. 1989:10:382-5.

3. Morizono T. Toxicity of ototopical drugs: Animal modeling. Ann Otol Rhinol Laryngol. 1990;99:42-5.

4. Jinn TH, Kim PD, Russell PT, Church CA, John EO, Jung TT, et al. Determination of ototoxicity of common otic drops using isolated cochlear outer hair cells. Laryngoscope. 2001;111:2105-8. 
5. Thorp MA, Kruger J, Oliver S, Nilssen EL, Prescott CA. Antibacterial activity of acetic acid and Burow's solution as topical otologic preparations. J Laryng Otol. 1998;112:925-8.

6. Thorp MA, Oliver SP, Kruger J, Prescott CA. Determination of the lowest dilution of aluminum acetate solution able to inhibit in vitro growth of organisms commomly found in chronic suppurative otitis media. J Laryng Otol. 2000;114:830-1.

7. Thorp MA, Gardiner IB, Prescot CA. Burow's solution in the treatment of active mucosal chronic suppurative otitis media determining an effective dilution. J Laryngol Otol. 2000;114:432-6.

Submit your next manuscript to BioMed Central and we will help you at every step:

- We accept pre-submission inquiries

- Our selector tool helps you to find the most relevant journal

- We provide round the clock customer support

- Convenient online submission

- Thorough peer review

- Inclusion in PubMed and all major indexing services

- Maximum visibility for your research

Submit your manuscript at www.biomedcentral.com/submit
Biomed Central 